\title{
ESTATUTO DE PROTECCIÓN AL MENOR DE EDAD EN EL CÓDIGO DEL TRABAJO DE 1931
}

\section{PROTECTION STATUTE OF THE MINOR IN THE LABOR CODE OF 1931}

\begin{abstract}
ANDREI CANDIANI GUERRA*
RESUMEN: El presente artículo analiza las características de la regulación legal del trabajo de menores, desde el Código del Trabajo de 1931 hasta la específica regulación del Decreto Ley $\mathrm{N}^{\circ}$ 2.200, conocido como "Plan Laboral". Previo a ello, analiza las condiciones políticas, económicas y jurídicas que posibilitaron e hicieron necesaria una regulación especial para el trabajo de menores, desde la revolución industrial, que generó las condiciones para la utilización masiva de mano de obra infantil, hasta el fenómeno de la descodificación, que dio paso a la dictación de leyes especiales en detrimento de un Código Civil, que perdía cada vez más fuerza regulatoria.

PALABRAS CLAVE: Revolución Industrial; Descodificación; Código del Trabajo de 1931; D.L. 2.200; trabajo de menores

ABSTRACT: This article analyzes the characteristics of legal regulation of child labor, since the Labor Code of 1931 to the specific regulation of Decree Law No. 2200, known as "Labor Plan". Previously, it analyzes the political, economic and legal conditions that made possible and necessary a special regulation for child labor, since the Industrial Revolution, which created the conditions for the widespread use of such labor, to the phenomenon of decoding, which led to the enactment of special laws in detriment of a Civil Code, which increasingly lost more regulatory power.
\end{abstract}

KEY WORDS: Industrial Revolution; decoding; Labor Code of 1931; D.L. 2.200; child labor

\section{INTRODUCCIÓN}

La Revolución Industrial significó un cambio cualitativo en las condiciones materiales de vida de la humanidad que generó una nueva práctica política, económica y social. En este último ámbito trajo consigo una serie de problemáticas sociales, que hasta ese momento eran desconocidas. La relación entre capital y trabajo cambia completamente, convirtiéndose el campesino y el artesano en obreros asalariados. La relación de trabajo entre el proletario y el burgués permite constatar que los intereses del capital no van necesariamente en la misma dirección que las preocupaciones de la persona humana. La necesidad de soluciones institucionales determinará el surgimiento de diversas doctrinas que buscarán, cada una a partir de un sustrato filosófico propio, reivindicar el valor de la persona y mejorar las condiciones materiales para el mundo obrero y asalariado.

Hasta ese momento la inmensa mayoría de la población vivía en los campos, dedicada a la sobrevivencia mediante actividades agropecuarias. Al llegar la Revolución Industrial a los campos se produjeron bolsones de cesantía que ocasionaron el traslado de grandes grupos hacia las ciudades en busca de mejores condiciones de vida.

\footnotetext{
${ }^{*}$ Licenciado en Ciencias Jurídicas y Sociales, Universidad de Chile. Ayudante de Historia del Derecho y de Derecho Minero, Universidad de Chile. Contacto: acandiani1990@gmail.com.
} 
En el plano jurídico, la recepción de las ideas del liberalismo político y económico significó una política de restricción para los gremios, como la Ley Le Chapelier francesa en 1789. El gremio es una institución corporativa que va en contra de los principios de la libre competencia. La legislación respectiva para ellos, organizaciones productivas anteriores a la Revolución Industrial, sirvió de pretexto para no permitir cualquier conato de organización de los trabajadores asalariados.

La ley de la oferta y la demanda también se aplicó para la contratación de mano de obra, derivándose de ello que una de las consecuencias más tristes fuese la incorporación de mujeres y niños a la cadena productiva. La abrogación de los derechos estatutarios, junto a una idea de igualdad inspirada en un rechazo a las normas del Antiguo Régimen, no contempló restricción alguna a la contratación de mujeres y niños.

Los efectos de esta transformación alcanzaron a abarcar en poco menos de un siglo todo el orbe. Chile no fue la excepción. Por lo tanto en este trabajo, haciendo eco del planteamiento del historiador Gabriel Salazar ${ }^{1}$, según el cual los niños son sujetos omitidos por la historia (Salazar, 2007: 7-11), consideramos necesario abordar el tratamiento jurídico que recibió el menor de edad, por parte del Derecho Laboral en Chile.

Los menores de edad también fueron trabajadores. Algunos ejemplos de esto se pueden encontrar en la minería, en que niños laboraron en largas jornadas en lugares como el norte salitrero, Copiapó $^{2}$ y Lota.

En efecto, el estatuto legal que el Derecho Laboral le confiere al menor de edad nos permite conocer algunos aspectos de la vida cotidiana del niño trabajador. El Derecho Laboral marca el ocaso del ideal codificador, basándose en las prácticas y costumbres de la cotidianeidad $^{3}$. La regulación jurídica se construye sobre la realidad que determinará el derecho. La norma se modificará bajo una lógica de ensayo y error. Ya no es posible pensar en un derecho de carácter universal que abarque todas las posibles situaciones de hecho.

El Derecho Laboral surgió bajo el impulso de dos concepciones ideológicas que trataron de responder a la problemática de la cuestión social: el Socialismo, en su versión utópica y marxista, y la Doctrina Social de la Iglesia. El primero, en su versión utópica, buscó una regulación jurídica de la relación laboral desde una perspectiva reformista, teniendo como exponentes principales a Robert Owen y Henri de Saint Simon. Había en él algunas alusiones al menor de edad. Se denunciaba, por ejemplo, las consecuencias médicas que traería la falta de sueño entre los niños que trabajaban. En su vertiente

\footnotetext{
${ }^{1}$ Revisando el libro Ser niño huacho en la Historia de Chile de Gabriel Salazar, el autor sostiene que existen actores dentro de la historia que no han sido tomados en consideración. Se señalan algunos casos vinculados a normas recopiladas de Archivos Judiciales, Reglamentos de Policía y manuscritos inéditos, que dan una idea sobre la situación en que se encontraba la población más pobre del país, en específico la infantil, y de cómo ellos absorbían en su formación y crecimiento las circunstancias que les rodeaban.

${ }^{2}$ En el Museo Regional de Copiapó se pueden apreciar algunas fotografías de niños trabajando en el mineral de plata.

${ }^{3}$ Un interesante análisis hace de esto Alejandro Guzmán Brito, citando a Natalino Irti y su artículo L'etá della decodificazione. En el artículo de Guzmán se indica cómo el derecho pasaría de una regulación común ya enfocada en el individuo solamente, hacia una legislación especial destinada al individuo en cuanto integrante de organizaciones o no. En Chile, Guzmán destaca que se "descodifica" el contrato de arrendamiento de servicios inmateriales (artículos 2006 a 2012 del Código Civil), aunque rechaza que eso haya significado una "fuga masiva" del Código Civil, manteniéndose firme y sin amenazas de declinación. Guzmán Brito, (1993), pp. 39-62.
} 
marxista, el Manifiesto del Partido Comunista no hace una alusión exacta al menor de edad, sino que lo circunscribe a la explotación del trabajador en general. En este sentido, la primera trata acerca de las hijas de obreros que son violentadas sexualmente por sus patrones, y la segunda sobre la significación del avance tecnológico en la producción, lo que simplifica las labores manuales, incitando a los dueños de los medios de producción a preferir el uso de mano de obra de mujeres y niños dado su menor costo (Marx y Engels, 2008: 68-71).

Respecto a la Doctrina Social de la Iglesia, nos centramos en el contenido de las encíclicas más ilustrativas: Rerum Novarum del 15 de mayo de 1891 y Quadragesimo Anno del 15 de mayo de 1931. La encíclica de Quadragesimo Anno no contiene ninguna mención alguna sobre este tema. Por su parte, la Rerum Novarum circunscribe el estatuto de protección del menor de edad en general a la familia. El niño es un objeto de protección dentro del núcleo familiar y no propiamente un sujeto de derecho ${ }^{4}$ :

- Pide evitar que los niños realicen labores en estaciones del año con condiciones climáticas insufribles que solamente podría realizar un hombre robusto.

- Los niños no deben entrar en el trabajo en talleres antes de la edad en que tengan el suficiente desarrollo de su cuerpo, inteligencia y alma.

- Existe una mención para la mujer y la naturaleza de su trabajo, de tipo doméstico. en beneficio de la educación de sus hijos y la prosperidad de su familia.

- Por último, existe una alusión a los distintos tipos de sociedades de socorro mutuo y que pueden ayudar a acercar una clase social con la otra. Dentro de los distintos fines benéficos de dichas entidades se encuentran previsiones para amparar a los hijos y la familia en general sobre enfermedades, imprevistos y cualquier accidente propio de las cosas humanas. Además de patronatos fundados para cuidar niños, niñas y jóvenes.

La competencia económica entre las sociedades completamente industrializadas y los dilemas morales que ambas doctrinas introducen en el mundo occidental van a llevar a una política de acercamiento entre la Iglesia Católica y el gobierno alemán. El lugar más probable para una revolución era Alemania. El marxismo y los movimientos inspirados en él encontraron un fértil espacio en ese país, por lo que el Estado alemán inicia una política de seguro social que lo deja en una posición económica desventajosa ante sus pares de occidente. Por esta razón, en 1890 fue convocada en Alemania, por el emperador Guillermo II, la Conferencia de Berlín, que fue apoyada por el Papa León XIII, en la que acudieron trece estados (Montt Balmaceda, 1998: 43-44), entre los que se encontraban Francia, Inglaterra, Bélgica, España y Suiza. Dicha conferencia tiene como antecedente la obra del canciller Otto Von Bismarck y la creación del Seguro Social, como respuesta frente a los sindicatos dominados mayoritariamente por el Partido Socialdemócrata Alemán (SPD). Esta conferencia significó un avance importante hacia la coordinación de los contenidos en

\footnotetext{
4 León XIII. Carta Encíclica Rerum Novarum del Sumo Pontífice León XIII sobre la situación de los obreros. [en línea] $\quad<$ http://www.vatican.va/holy_father/leo_xiii/encyclicals/documents/hf_1xiii_enc_15051891_rerum-novarum_sp.html> [consulta: 05 octubre 2011].
} 
las legislaciones europeas, en específico, respecto al trabajo infantil y de la mujer ${ }^{5}$. La Conferencia de Berlín fue un paso importante hacia la internacionalización del Derecho del Trabajo.

Al término de la Primera Guerra Mundial, con el surgimiento de la revolución en Rusia y las consecuencias económicas, el Título XIII del Tratado de Versalles, en sus artículos 387 a 427 (Montt Balmaceda, 1998: 45-47), crea la Oficina Internacional del Trabajo, posterior Organización Internacional del Trabajo (Montt Balmaceda, 1998: 45-47). El trabajo y la situación social del obrero es un factor fundamental en el sostenimiento de la paz mundial.

En Chile, las primeras leyes laborales datan de los albores del siglo XX, y sobre el punto que nos interesa podemos citar:

- El proyecto de ley de Malaquías Concha Ortiz llamado "Ley de trabajo de los menores, salubridad y seguridad en los talleres" de 1901 (Thayer Arteaga, 2008: 28);

- Proyecto de Ley del Trabajo del 2 de junio de 1919, presentado por siete diputados conservadores. En dicho proyecto figura una prohibición de trabajo en lugares peligrosos a menores de edad. Y se prohíbe el trabajo a menores de 12 años (Thayer Arteaga, 2008: 28).

- El mundo liberal también se hizo cargo de esta problemática, siendo presidente Arturo Alessandri Palma, presentándose al Parlamento el proyecto de Código del Trabajo, redactado por Moisés Poblete Troncoso. Este proyecto nunca fue despachado, formado por 620 artículos y dividido en cuatro libros (Walker Linares, 1957: 155).

El surgimiento del Derecho Laboral propiamente tal se vio a través de las leyes que posteriormente configurarían el Código del Trabajo de Chile de 1931, esto es, las leyes número 4053 a 4058 refundidas, la ley 4059 y el Decreto 34 de 1926.

\section{LA DESCODIFICACIÓN Y EL DERECHO DEL TRABAJO}

La dictación del Código del Trabajo en 1931 permitió el surgimiento de una nueva doctrina jurídica, que se independiza de la tradición del Código Civil, siguiendo de esta manera una tendencia mundial. Con la predominancia del Código Civil rigieron principios individualistas en la legislación general, dado que el sistema giraba principalmente en torno a aquél.

Sin embargo, la desigualdad de poder de negociación entre capitalistas y trabajadores impulsó a una modificación: la sola libertad de contratación se vuelve insuficiente con las asimetrías existentes, cobra mayor relevancia la institución del Sindicato, y pierden terreno los ideales liberales decimonónicos en torno a las relaciones de

5 Universitat de Barcelona. La Conferencia de Berlín de 1890. [en línea] $<$ http://www.ub.edu/ciudadania/hipertexto/evolucion/introduccion/trabajo/trabf5.htm $>$ [consulta: 18 octubre 2011]. 
trabajo. Las circunstancias sociales y políticas importaron un contexto propicio para la modificación del ordenamiento jurídico y pasar a una lógica del sistema.

De esta manera, el Código Civil pierde fuerza como centro del ordenamiento jurídico, pasando a tener un carácter residual, limitándose a regular ciertas instituciones de forma genérica o siendo una disposición legal disponible a falta de una legislación especial sobre un asunto.

Las modificaciones respecto al estatuto del menor de edad se encuentran implicadas en este contexto. Más aún teniendo en cuenta su situación social empobrecida en múltiples casos.

El paso de un Estado liberal decimonónico a uno más presente en el desarrollo económico y social se concreta en nuestro país con la dictación de la Constitución de 1925. Pero lo anterior no se entiende si no se atiende al contexto nacional e internacional en que se inspiró.

Con respecto al fenómeno mundial de la Descodificación, vale señalar el análisis del profesor italiano Natalino Irti.

Irti considera que ya no es posible quedarse en la "nostalgia" de la intención codificadora, centralizando la vida jurídica en torno al Código Civil, sino que ya es tiempo de iniciar una nueva forma de analizar el derecho en función de la "lógica del tiempo propio" (Irti, 1992: 38). La consecuencia es que el Código Civil pierde su posición anterior, una suerte de "ocaso de la ideología tolemaica" en palabras del autor, como norma reguladora de las relaciones entre individuos.

Pero esto no termina allí: el jurista descubre nuevos principios, autónomos de la lógica del Código. Dichos principios derogan temporalmente los anteriores principios del Código, y sirven de germen de un nuevo derecho. Este fenómeno es reflejo de una crisis del modelo de Estado liberal decimonónico, no solo en lo jurídico sino también en lo económico, donde nuevos y viejos grupos sociales entran en escena y presionan por un marco de protección jurídica mayor para sus intereses. El Código Civil se hace insuficiente; van surgiendo normas complementarias que modifican la relación entre el Código y el resto de la legislación, y esto no parece tener término, pues no solamente áreas como el Derecho Laboral nacen de esto, sino que ha permitido el surgimiento de otras ramas mediante el mismo procedimiento (Irti, 1992: 39-41).

El Código Civil se transforma de esta manera tanto en un marco residual, donde a sus disposiciones solamente se acudiría en caso de que la legislación especial no tuviera una normativa que abarcara situaciones no contempladas en estas normas, o como disposición para instituciones jurídicas amplísimas (Irti, 1992: 39-41).

Las nuevas normas laborales tienen una lógica diferente a las generales: surge una nueva forma de razonar en torno a ellas, no un mero arbitrio. Si desentona con los principios generales, no es que vaya en contra de ellos, sino que existe un nuevo criterio de valoración. En otras palabras, dentro del gran sistema jurídico surge una "lógica de sector", que no es contraria a la totalidad (Irti, 1992: 58-59).

Las circunstancias sociales y políticas fuerzan los cambios. Hasta 1914, el Código Civil se tiene como garante de la unidad del ordenamiento, fiel a las bases liberales burguesas del siglo XIX (Irti, 1992: 59). En aquel entonces las demás normas, separadas de la línea del Código Civil, no eran más que especificaciones de las disposiciones del Código, o revestían el carácter de leyes especiales para casos no contemplados en éste. Pero el surgimiento de nuevos micro sistemas jurídicos no significa el rompimiento de la unidad 
del sistema mayor. Irti reconoce que la unidad desde entonces está dada de forma externa al Código: ya no es aquel quien da, por su propio texto, la unidad (Irti, 1992: 61-62).

¿Dónde encuentra entonces dicha unidad rota su vértice de unión? Irti es enfático: en la Constitución Política. La jerarquización de las normas toma un papel relevante, dejando aún más marginado al Código Civil: la norma general puede estar perfectamente fuera de su texto. Desde ahora, las normas pasan a ser realizadoras de objetivos y programas constitucionales (Irti, 1992: 62). En otras palabras, pasamos de un mono-sistema a un poli-sistema, unificado por las directrices constitucionales.

La Constitución Política es la que determina los principios generales del sistema. Su fuerza jurídica irradia a todos los micro sistemas, creando a su vez un sistema mayor y coherente. Para resolver antinomias se recurre a principios de interpretación y de jerarquización, como la sucesión de norma general a especial (tanto en criterios cronológicos como de especialidad), norma excepcional a norma especial, reenvíos ${ }^{6}$, por autodefinición ${ }^{7}$, criterio literal, criterio lógico-sistemático y los principios generales del Estado $^{8}$.

Tal fenómeno descrito afectó a Chile en la década de los años veinte del siglo XX. A continuación, describiremos las regulaciones que nos interesan al caso.

Desde luego, existieron normas precedentes al Código del Trabajo de 1931. Un análisis más profundo puede verse en la tesis matriz de este trabajo (Candiani, 2015).

\section{EL MENOR DE EDAD EN LAS LEYES SOCIALES}

El Código del Trabajo de 1931 tuvo una vigencia prolongada. No solo se aplicó su texto base sino también variadas disposiciones complementarias surgidas ante coyunturas políticas y económicas.

Las regulaciones introducidas abarcaron una pluralidad de casos. Comprendieron tanto a varones como mujeres.

3.1 PROHIBICIONES DE DESEMPEÑAR CIERTAS LABORES Y AUTORIZACIONES DEL PADRE, MADRE O QUIEN TUVIERE A SU CARGO EL MENOR.

Se establece la libre administración de los salarios que los menores de edad percibiesen, así como el pago de estos sin la intervención de sus representantes legales ${ }^{9}$. Esto se condice con la norma del Código Civil respecto al Peculio Profesional o Industrial del hijo sujeto a patria potestad (artículo 250 número 1$)^{10}$.

\footnotetext{
${ }^{6}$ Cuando la norma misma hace un reenvío a otra norma. (Irti, 1992: 71).

${ }^{7}$ Cuando la norma misma se pone como especial al ser confrontada con otra norma. Ídem.

${ }^{8}$ Hace referencia a los criterios programáticos constitucionales mencionados anteriormente.

${ }^{9}$ El artículo 38 del Código dice: "Los obreros menores de dieciocho años, de ambos sexos, y las mujeres casadas, recibirán válidamente hasta el cincuenta por ciento del salario devengado por su marido declarado vicioso, a petición de ella, por el respectivo Juez del Trabajo. El patrón deberá hacer los descuentos que correspondan. Igual derecho podrá otorgar el Tribunal a la madre respecto de los salarios que ganen sus hijos menores".

${ }^{10}$ Artículo 250 del Código Civil: "La patria potestad confiere el derecho legal de goce sobre todos los bienes del hijo, exceptuados los siguientes:
}

1. Los bienes adquiridos por el hijo en el ejercicio de todo empleo, oficio, profesión o industria. Los bienes comprendidos en este número forman su peculio profesional o industrial; 
Se exige la autorización del padre o madre, o del abuelo paterno o materno, o de las instituciones que tengan a cargo el cuidado del menor, respecto de la celebración de contratos laborales por parte de éste. Se establece así mismo que no podrán realizar trabajos en recintos subterráneos, en la elaboración o manipulación de materiales inflamables, limpieza de motores y maquinaria pesada, y otros trabajos que sean gravosos para el físico del menor ${ }^{11}$. Dicha norma concuerda con la Recomendación $\mathrm{N}^{\circ} 125$ sobre condiciones de empleo de los menores en trabajo subterráneo de la Conferencia Internacional del Trabajo de 1965 (Montt Balmaceda, 1998: 285), aunque el Código las prohíbe expresamente, la normativa internacional se limita a establecer ciertas condiciones mínimas de seguridad e higiene, sin prohibir ese tipo de trabajo ${ }^{12}$. En esta materia la legislación chilena se adelantó a la internacional.

Se permite que los menores de catorce y mayores de doce años de edad desempeñen actividades remuneradas, pero se prohíben las faenas relativas a industrias, a menos que sus empleados correspondan a una misma familia, y que esté a cargo de uno de sus miembros. Exige también este artículo un registro que debía llevar el patrón o jefe de la industria de los menores de dieciséis años ${ }^{13}$.

Se prohíbe a los menores de dieciocho años toda labor en trabajos nocturnos en establecimientos industriales, salvo que solo trabajen miembros de una misma familia en él, y bajo la autoridad de uno de sus miembros. Menciona como excepción a los varones mayores de dieciséis respecto a trabajos que no pueden abandonarse en el horario

2. Los bienes adquiridos por el hijo a Título de donación, herencia o legado, cuando el donante o testador ha estipulado que no tenga el goce o la administración quien ejerza la patria potestad; ha impuesto la condición de obtener la emancipación, o ha dispuesto expresamente que tenga el goce de estos bienes el hijo, y

3. Las herencias o legados que hayan pasado al hijo por incapacidad, indignidad o desheredamiento del padre o madre que tiene la patria potestad.

En estos casos, el goce corresponderá al hijo o al otro padre, en conformidad con los Artículos

251 y 253.

El goce sobre las minas del hijo se limitará a la mitad de los productos y el padre que ejerza la patria potestad responderá al hijo de la otra mitad”.

${ }^{11}$ El artículo 46 indica: "Pueden contratar libremente la prestación de sus servicios los mayores de dieciocho años, quienes serán considerados mayores de edad para todos los efectos de este Texto. Los menores de dieciocho años y mayores de catorce necesitarán autorización expresa del padre o madre y en su defecto del abuelo paterno o materno, y a falta de ellos, de las personas o instituciones que hayan tomado a su cargo al menor; pero, no serán admitidos en trabajos subterráneos, en la elaboración o manipulación de materias inflamables, en la limpieza de motores o piezas de transmisión mientras funcionan las maquinarias, en la derripiadura de los cachuchos de la salitreras o en faenas que requieran fuerzas excesivas y en otros trabajos calificados de peligrosos o insalubres, no podrán trabajar más de ocho horas".

12 Organización Internacional del Trabajo. Recomendación $n^{\circ} 125$ sobre las condiciones de empleo de los $\begin{array}{lllll}\text { menores } & \text { (trabajo subterráneo), } & \text { [en } & \text { línea] }\end{array}$ <http://www.icbf.gov.co/transparencia/derechobienestar/recomendacion/recomendacion_oit_0125_65.html> [consulta: 17 octubre 2011].

${ }^{13}$ El artículo 47 dice: "Los menores de catorce años y mayores de doce, podrán trabajar siempre que hubieren cumplido la obligación escolar; pero no podrán hacerlo en los establecimientos industriales ni aun en calidad de aprendices, salvo aquellos en que se empleen únicamente

miembros de una misma familia bajo la autoridad de uno de ellos.

Para los efectos de este artículo todo patrón o jefe de establecimiento industrial, deberá llevar un registro de inscripción de los menores de dieciséis años, con indicación de la fecha del nacimiento y con las demás menciones que exija el Reglamento". 
nocturno $^{14}$. Esta prohibición y sus excepciones coinciden con las estipuladas en el Convenio $\mathrm{N}^{\mathrm{o}} 5$ sobre trabajo nocturno de los menores de la OIT $^{15}$. Destaca también el artículo que el varón mayor de dieciséis años podrá desempeñar labores en ciertas industrias determinadas por reglamento, siendo una mayoría de edad especial para este tipo de labores, en contraste con la norma del Código Civil de aquellos años que la fijaba a partir de los veinticinco años ${ }^{16}$.

Se establece la prohibición de trabajar en representaciones públicas, como teatros, circos o cafés u otros lugares con fines de lucro. Excepcionalmente se podía permitir el empleo de niños en representaciones de esta naturaleza, con una autorización del gobernador, previo informe del inspector del trabajo respectivo ${ }^{17}$. En esta materia vuelve el Código del Trabajo a adelantarse a la legislación internacional, pues el Convenio $\mathrm{N}^{\mathrm{o}} 33$ sobre la edad mínima en trabajos no industriales de la OIT (Montt Balmaceda, 1998: 285), permitía que los menores desempeñasen dichas labores, limitándose solo a enumerar ciertas condiciones mínimas de higiene y seguridad. El Código del Trabajo, si bien no prohíbe absolutamente esto, lo limita severamente.

Respecto al contrato de trabajo, se exige la autorización del representante legal, y a falta de éste, de la madre del menor, del abuelo paterno o materno, o de quienes tengan a su cuidado el menor. Para la contratación de menores de catorce años se pide además un certificado de cumplimiento de su educación escolar.

Se exige la presencia y firma del representante del empleado menor de dieciocho años, o por quién lo tenga a su cuidado, respecto de los contratos de trabajo. Se relaciona con el artículo 46 de la misma ley.

El artículo 123 de la ley vuelve sobre la idea de que los trabajadores menores de edad debían recibir sus remuneraciones sin la intervención de sus representantes, y tendrían su libre administración.

\subsection{ESCOLARIDAD: EXIGENCIA Y PROHIBICIONES.}

Darío Salas hizo un duro análisis de la realidad escolar y de alfabetización de Chile en su libro El Problema Nacional, donde denunció que, según el censo de 1907, había una tasa de analfabetismo del 60\% de la población (Salas, 2011: 31). La frase más recordada de esta obra es la ilustración de que la cantidad de analfabetos era tal que "Colocados en fila,

\footnotetext{
${ }^{14}$ El artículo 48 dice: "Queda prohibido a los menores de dieciocho años y a las mujeres, todo trabajo nocturno en establecimientos industriales, que se ejecute entre las veinte y las siete horas, con excepción de aquellos en que únicamente trabajen miembros de una misma familia, bajo la autoridad de uno de ellos. Exceptuándose de esta prohibición a los varones mayores de dieciséis años, en las industrias que determine el Reglamento, tratándose de trabajos que, en razón de su naturaleza, deban necesariamente continuarse de dia y de noche".

15 Organización Internacional del Trabajo. Convenio $n^{o} 5$ sobre el trabajo nocturno de los menores (industria), 1919. [en línea] < http://www.ilo.org/ilolex/cgi-lex/convds.pl?C006> [consulta: 17 octubre 2011].

${ }^{16}$ Dicha normativa fue modificada por la Ley 7612 del 21 de octubre de 1942, que redujo de veinticinco a veintiún años la mayoría de edad. Esto fue modificado a su vez el 1 de junio de 1993 por la Ley 19221.

17 Artículo 50: "No se permitirá el trabajo de los niños menores de catorce años en las representaciones públicas en los teatros, circos cafés, o cualquier otro lugar de diversión con fines de lucro. Sin embargo, el gobernador, previo informe del inspector del Trabajo respectivo, podrá excepcionalmente, autorizar el empleo de niños para la representación de piezas determinadas".
} 
a cincuenta centímetros uno de otro, formarían una columna de 800 kilómetros de largo, la distancia que media entre Santiago y Puerto Montt" (Salas, 2011: 32). Salas abogó por una escolaridad obligatoria para los menores chilenos, y cita una serie de normativas existentes en la época de publicación del libro, a saber, los artículos 222, 323, 428 y 438 del Código Civil $^{18}$, sobre la obligación de procurar enseñanza al hijo o pupilo; y el artículo 494, número 15 , del Código Penal ${ }^{19}$, que sancionaba la falta de cumplimiento de aquella obligación, aunque el mismo Salas reconoce que durante cuarenta años (desde la entrada en vigencia del Código Penal) no pasaba de ser "letra muerta" (Salas, 2011: 37). A esto le suma la Ley de Municipalidades que, en su artículo 115, manda a los alcaldes a poner en práctica esta obligación (Salas, 2011: 37).

La influencia de Salas fue significativa, pues durante el gobierno de Arturo Alessandri Palma se logró la aprobación, con varias enmiendas respecto al proyecto original, de la Ley de Instrucción Obligatoria en 1920, a lo que podemos recordar las palabras del mismo Salas, cuando señaló, en 1917, que la obligatoriedad era un resguardo a la igualdad de oportunidades, y que por ello debía ser dirigida y financiada por el Estado. Es decir, implicaba una escuela común que sirviera para combatir la desigualdad social, pero en vez de referirse a los padres se refiere a esto como un deber del Estado ${ }^{20}$.

Los menores de dieciocho años que no hayan recibido instrucción escolar tienen el derecho de disponer dos horas diarias de las destinadas a trabajo a dicha preparación. Estas horas no dan derecho a remuneración ${ }^{21}$.

Sobre el reglamento interno de la empresa, entre las once exigencias mínimas, pide que contenga la forma de comprobación del cumplimiento de las obligaciones escolares de los empleados menores de edad ${ }^{22}$.

Dentro de la obligación de entregar libretas con el reglamento interno a los trabajadores, se agrega que en el caso del menor de edad deberá entregarse dicha libreta al padre, tutor o persona que tenga a su cuidado el menor ${ }^{23}$.

\subsection{RELATIVO AL PADRE O MADRE EXTRANJERO Y SU EMPLEABILIDAD.}

\footnotetext{
${ }^{18}$ Estos artículos sufrieron una modificación en 1998 por parte de la Ley 19.585 del 26 de octubre de ese mismo año, atendiendo a la reforma constitucional de aquel año, en la cual se termina con la distinción entre hijos naturales y legítimos.

${ }^{19}$ Artículo 494, número 15, del Código Penal: "Los padres de familia o los que legalmente hagan sus veces que abandonen a sus hijos, no procurándoles la educación que permiten y requieren su clase y facultades”. El texto de esta norma no ha sufrido modificación alguna desde su entrada en vigencia.

${ }^{20}$ (Salas, 2011). Página XXV (introducción de Sol Serrano).

${ }^{21}$ Artículo 51: "Se dejarán libres, por lo menos, dos horas diarias de las destinadas al trabajo, a los menores de dieciocho años, que no hayan recibido instrucción escolar. Dichas horas no darán derecho a remuneración".

${ }^{22}$ Artículo 93, n 11: “El reglamento interno deberá contener, por lo menos, las siguientes disposiciones: (...) 11) La forma de comprobación del cumplimiento de las leyes de previsión obrera, de servicio militar obligatorio, de carnet de identidad, y en caso de menores, de haberse cumplido la obligación escolar".

23 Artículo 94: "Los reglamentos internos deberán ponerse en conocimiento de los obreros quince días antes de la fecha en que comiencen a regir, y hallarse fijados, a lo menos, en dos sitios visibles del lugar del trabajo. Además, los patrones deberán entregar gratuitamente a todos los obreros, una libreta que contenga el texto impreso del reglamento interno de la empresa y las anotaciones sobre individualización del obrero que determine el reglamento. En caso de tratarse de obreros menores de dieciocho años, la libreta será entregada al padre, tutor o curador de aquellos, o a quien los tuviere a su cuidado”.
} 
Se protege laboralmente, considerándose como chileno dentro del total de empleados, al padre o madre extranjero cuyo cónyuge sea chileno, o que habiendo enviudado, haya tenido hijos chilenos ${ }^{24}$. De esta forma se otorgan mayores posibilidades de contratación del padre o madre extranjero, asegurando un medio de sustentabilidad a la familia del menor, o al menos una mayor seguridad en la mantención del puesto de trabajo.

\subsection{RELATIVO A LA SEGURIDAD SOCLAL.}

En materia de seguridad social, la ley consagró un estatuto especial para el menor de edad que se tradujo en diversas normas.

Así, por ejemplo, en lo relativo al derecho a renta vitalicia, se establece que el cónyuge sobreviviente podía recibir el treinta por ciento del salario anual del fallecido. En el caso de que la mujer fuere la sobreviviente, sin casarse en segundas nupcias, se reduce un veinte por ciento de esta renta percibida a favor de los hijos del fallecido ${ }^{25}$. Los hijos legítimos tenían derecho a percibir una pensión equivalente al cuarenta por ciento del salario anual ${ }^{26}$.

Se extiende este beneficio de pensión a las personas que vivían a cargo y a expensas del fallecido, entre los que se menciona a los menores de edad ${ }^{27}$, pero solo pudiendo percibirla hasta los dieciséis años ${ }^{28}$.

Los menores de dieciocho años debían percibir sus indemnizaciones o pensiones legales por medio de sus padres o representantes legales. Si el menor no tuviese padres ni guardador, correspondía al Juez del Trabajo la designación de un guardador especial para estos efectos $^{29}$. Este artículo no implica que el tutor del menor tenga el derecho legal de

\footnotetext{
${ }^{24}$ Artículo 116: "Para computar la proporción a que se refiere el artículo anterior [artículo 115], se seguirán las reglas que a continuación se expresan: (...) 3) Se tendrá como chilenos a los extranjeros cuyo cónyuge sea chileno o que sean viudos de cónyuge con hijos chilenos; (...).

25 Artículo 287: "El cónyuge sobreviviente tendrá derecho a una renta vitalicia igual al 30 por ciento del salario anual de la víctima. Si el cónyuge sobreviviente fuere varón, sólo tendrá derecho a la renta en caso de que esté inhabilitado para el trabajo; y si el cónyuge sobreviviente fuere mujer, perderá su derecho a la renta en caso de que contrajere segundas nupcias, y su renta, reducida para este efecto a un 20 por ciento, acrecerá la pensión de los hijos del accidentado fallecido”.

26 Artículo 288: “Los hijos menores de dieciséis años, sean legítimos, tendrán derecho a percibir, en conjunto, hasta que cumplan esa edad, una pensión igual al 40 por ciento del salario anual, si hubiere cónyuge con derecho a pensión vitalicia, e igual al 60 por ciento, en caso contrario. La pensión será divisible entre los hijos por iguales partes, pero en ningún caso la pensión de uno de ellos excederá del 20 por ciento del salario anual del padre, y habrá entre ellos derecho a acrecer hasta que la pensión de cada uno alcance al máximo señalado".

${ }^{27}$ Importante destacar que se habla del "menor de edad" sin entrar a diferenciar entre las categorías jurídicas existentes en aquellos años respecto a los hijos.

${ }^{28}$ Artículo 290: “A falta de cónyuge, de ascendientes y descendientes legítimos e ilegítimos, tendrán derecho las personas, sean parientes o no, que, a la fecha del accidente, vivían a cargo y a expensas de la víctima. El derecho consistirá en una renta vitalicia si los beneficiarios se encontraren absolutamente incapacitados para el trabajo, o en una pensión temporal, pagadera hasta los dieciséis años, si se tratare de menores de edad. Las sumas de las rentas y pensiones no podrán exceder de una cuota igual al 20 por ciento del salario anual, ni cada renta o pensión, del 10 por ciento, de dicho salario. Las rentas y pensiones individuales se reducirán proporcionalmente si concurrieren más de dos beneficiarios".

${ }^{29}$ Artículo 301: "Las indemnizaciones o pensiones legales podrán pagarse directamente a los accidentados que sean mujeres casadas, sin que intervengan sus representantes y los finiquitos que ellas otorguen serán válidos. Los menores de dieciocho años necesitarán la intervención de sus padres o representantes legales.
} 
goce sobre estos bienes, sino que solamente es un intermediario en la percepción de dichas indemnizaciones y pensiones. Concuerda con el artículo 250 número 1 del Código Civil a propósito del peculio profesional o industrial de los hijos, los que para efectos de dicha norma se consideraban mayores de edad para la administración y goce de su peculio ${ }^{30}$.

Se protege procesalmente a los menores de dieciséis años excluyéndolos del tiempo de prescripción de la acción para reclamar las indemnizaciones, rentas o pensiones. El plazo de prescripción era de dos años a partir del accidente para los demás trabajadores ${ }^{31}$. En esta materia el Código del Trabajo se distancia del Código Civil, pues en este último en el artículo 2515 indica un plazo de prescripción de las acciones judiciales de tres años para las ejecutivas y de cinco para las acciones ordinarias. Mientras que en lo respectivo a la suspensión de la prescripción, se limita la ley laboral a enunciar la exclusión del varón menor de dieciséis años de esta. El artículo 2520 del Código Civil establece la interrupción a favor de los menores de edad, en relación con el artículo 2509 número 1, sin embargo, a la época de la dictación del Código del Trabajo, la mayoría de edad estaba fijada en los veinticinco años, estableciéndose una mayoría de edad especial para estos casos dentro de la legislación laboral sobre los varones mayores de dieciséis y menores de veinticinco $\operatorname{años}^{32}$.

\subsection{EN LO RELATIVO A LA MADRE DEL MENOR.}

En cuanto a la protección de la maternidad es importante destacar que la ley consagra un estatuto de sala cuna. Se obliga a los establecimientos con veinte o más obreros a tener en salas anexas y separadas del local de trabajo, un lugar para que las madres empleadas pudieran amamantar a sus hijos lactantes, con las condiciones de higiene y seguridad determinadas por el reglamento ${ }^{33}$.

\subsection{DISPOSICIONES PRECEDENTES INCORPORADAS AL TEXTO DEL CÓDIGO.}

El estatuto laboral del menor de edad bajo la vigencia del código de 1931 tuvo un antecedente importante en la Ley $\mathrm{N}^{\circ} 4059$ del año 1924, la que informa los artículos 38 y 53 del Código del Trabajo de 1931. Dentro de su temática, abarca el derecho de los

\footnotetext{
Tratándose de menores que no tengan padres ni guardador, el juez del Trabajo le nombrará un guardador especial, para los efectos de percibir las indemnizaciones o pensiones".

${ }^{30}$ Artículo 251 del Código Civil: "El hijo se mirará como mayor de edad para la administración y goce de su peculio profesional o industrial, sin perjuicio de lo dispuesto en el artículo 254”.

31 Artículo 303 del DFL 178, Código del Trabajo de 1931: "Las acciones para reclamar las prestaciones, indemnizaciones, rentas o pensiones a que se refiere este Título, prescriben en el término de dos años, a contar desde la fecha del accidente. Esta prescripción no correrá contra los menores de dieciséis años".

${ }^{32}$ Con la reforma al Código Civil efectuado por la Ley 7612 de 1942, pasa al rango de varones entre dieciséis y veintiún años de edad.

33 Artículo 315: "Los establecimientos que ocupan veinte o más obreros de cualquiera edad o estado civil, deberán tener salas anexas e independientes del local de trabajo, en donde las mujeres puedan amamantar a sus menores de un año y dejarlos mientras estén en el trabajo. Las salas-cunas deberán reunir las condiciones de higiene y seguridad que determine el reglamento".
} 
empleados menores de edad recibirían válidamente el pago sin intervención de sus representantes legales, reconociéndoseles la libre administración de ella ${ }^{34}$.

La distinción entre hijos legítimos e ilegítimos no es tan marcada como en el Código Civil, pese a estar mencionada. Segundo, el estatuto de 1931 posee la concepción del menor de edad dentro de una familia, traduciéndose en que siempre necesita la autorización de un pariente para trabajar, principalmente el padre o la madre. Hay que plantearse la pregunta de si el derecho laboral contempla un refugio para el menor contra el padre o madre en caso de abusos.

A falta de hijos legítimos sobrevivientes, las sumas acumuladas pasarían a los otros herederos, considerándose a los hijos ilegítimos ${ }^{35}$.

Dicha ley se vio complementado por otras de carácter especial anteriores al código y que no fueron incluidos en éste, en específico la Ley $\mathrm{N}^{\circ} 4059$ publicada el 27 de septiembre de 1924, y el Decreto 34 publicado el 3 de marzo de 1926.

Sobre el Decreto 34, la única mención atingente trata sobre la cobertura en asistencia médica y farmacéutica a los hijos del trabajador ${ }^{36}$.

\subsection{DISPOSICIONES COMPLEMENTARIAS DURANTE LA VIGENCLA DEL CÓDIGO.}

A lo largo de la vigencia del Código del Trabajo de 1931 se fueron dictando numerosas disposiciones con el fin de perfeccionar sus alcances. Ciertas materias requirieron ser incorporadas mediante normas anexas, las que fueron recopiladas por Juan Díaz Salas en sus ediciones del Código, en colaboración con Alberto Ruiz de Gamboa en los tomos III y IV de la colección, nutriéndose con varias leyes y algunos dictámenes, y organizando este trabajo en forma temática. La obra de Díaz Salas abarca la normativa creada entre los años 1931 y 1984, es decir, más de 50 años siguiendo las variaciones sufridas por la legislación laboral.

\footnotetext{
${ }^{34}$ El artículo 14 de la ley 4059 dice: "Los empleados menores de edad y las mujeres casadas, aunque no estén divorciadas ni separadas de bienes, recibirán válidamente el pago, sin intervención de sus representantes legales, y tendrán la libre administración de sus emolumentos".

${ }^{35}$ Artículo 25: "El total que quedare a nombre del empleado a su fallecimiento, en su cuenta de ahorro y prevision, corresponderá, por mitades, a su cónyuje sobreviviente y a sus herederos lejitimarios, en el órden y forma en que son llamados a la herencia segun las reglas de la sucesion intestada. A falta de cónyuje o de tales herederos, la totalidad pertenecerá a dichos herederos o al cónyuje, segun los

casos. A falta de estos herederos y cónyuje, las sumas acumuladas pasarán a los otros herederos legales o a los testamentarios del difunto y, a falta de todos éstos, a sus hijos ilejítimos y, en último término, a sus padres ilejítimos, siempre que la calidad de tales constare con anterioridad al fallecimiento del empleado”.

${ }^{36}$ Artículo 13 del Decreto 34: "Los asegurados que desearen estender a sus familias los beneficios de asistencia médica i farmacéutica comprendidos en los incisos a) y d) del artículo 15, abonarán semanalmente a la Caja respectiva, una cuota complementaria del 5 por ciento de su renta, sueldo o salario semanal. En este caso los patrones $i$ el Estado no estarán obligados a contribucion alguna. Para los efectos de este artículo se consideran como miembros de la familia, el cónyuje del asegurado, sus hijos lejítimos sus hijos naturales, sus ilejítimos reconocidos, sus padres lejítimos o naturales y en jeneral todos aquellos a quienes el asegurado debe alimentos, en conformidad a la lei. Sin embargo, las personas indicadas sólo gozarán del derecho que concede este artículo si vivieren con el asegurado y a sus espensas, salvo los padres lejítimos o naturales que no estuvieren a su vez obligados al seguro que establece esta lei”.
} 


\subsubsection{REGULACIÓN RELATIVA A LA EDUCACIÓN DEL MENOR DE EDAD.}

Durante la vigencia del Código del Trabajo surgieron diversas contingencias que impulsaron modificaciones a la legislación laboral en esta materia. La nueva legislación no hizo desaparecer el trabajo infantil, pese a que positivamente descendió la tasa de dicho trabajo en algunos rubros y se pudo apreciar un alza en la escolaridad, retrasando el ingreso a la vida laboral (Rojas Flores, 2010: 351).

La primera medida para proteger y regular la situación del menor de edad aparecida después de la publicación del Código del Trabajo, data del año 1932, apenas uno después de la entrada en vigencia de esta legislación: el Reglamento 485 del 7 de mayo. En su artículo único ordena confeccionar un registro de obreros menores de 16 años, siendo obligatoria la anotación de las horas libres de las que dispondría el menor contratado para su educación escolar (Ruiz de Gamboa y Díaz Salas, 1942: 368).

Posteriormente, en el Dictamen 66 de la Dirección del Trabajo, No 10,581 del veintisiete de septiembre de 1940 (Ruiz de Gamboa y Díaz Salas, 1942: 46), se hace referencia a los artículos 28, 46, 47 y 51 de la ley (Ruiz de Gamboa y Díaz Salas, 1942: 46). Dicha interpretación administrativa surge a partir de una consulta sobre dos puntos:

a. Si los menores de 18 años pueden trabajar más de 8 horas diarias, y

b. Si los menores de 18 años y mayores de 14 años deben acreditar haber cumplido con la obligación escolar para poder trabajar más de 8 horas diarias.

No obstante lo anterior, es el único dictamen emitido durante la vigencia del Código que involucrase directamente a menores de edad.

Respecto del primer punto, se enfatiza que los menores de 18 años en ningún caso pueden trabajar más de 8 horas diarias, pues la prohibición es absoluta. En cuanto al segundo punto, la Dirección del Trabajo expresa que los menores de 14 y mayores de 12 años pueden trabajar siempre que se haya cumplido la obligación escolar, sin embargo se entiende que no es posible que dicha obligación se cumpla en establecimientos industriales, aunque reúnan dicha exigencia. Sólo se exige que deban acreditar con certificados correspondientes que se ha cumplido con la obligación escolar, de lo contrario, el patrón debe concederles las 2 horas referidas en el artículo 61 (Ruiz de Gamboa y Díaz Salas, 1942: 46).

Por último, sobre el sustrato fáctico, la Dirección se refiere al trabajo de menores en las faenas de extracción de ripio y arena en el río Mapocho. El organismo indica que el día trece de julio de 1942 la Alcaldía de Santiago emitió el oficio No 166 por el que consultaba a la Dirección si se debía permitir o no el trabajo de menores de 18 años en dichas faenas. Se indicó que eran trabajos que requerían de gran fuerza física y de condiciones insalubres, pero una prohibición acarrearía un grave problema económico para el gremio arenero, pues dichas labores se realizaban principalmente por familias completas. Se consultó un informe previo de la Sección Técnica de Higiene y Seguridad Industriales de la Dirección del Trabajo, indicando que debía prohibirse cualquier labor de menores de edad, ya que estas no eran compatibles con el desarrollo psíquico y físico de los menores 61 (Ruiz de Gamboa y Díaz Salas, 1942: 46).

Las dos últimas medidas fueron tomadas por el gobierno de Eduardo Frei Montalva. Estas fueron la Ley N 17.301 que creó la corporación llamada "Junta Nacional de Jardines Infantiles" (22 de abril 1970), y la Ley 17301 sobre la obligación de tener salas cunas en las instituciones, servicios, empresas o establecimientos fiscales, semifiscales, municipales o 
de administración autónoma que ocupen 20 o más trabajadores (artículo 33 de dicha norma). Ambas medidas se orientan al cuidado de hijos de trabajadoras menores de edad (Díaz Salas, 1970: 529).

\subsubsection{REGULACIÓN RELATIV A A BENEFICIOS PREVISIONALES.}

No vuelve a desarrollarse un tratamiento específico a los menores sino hasta 1957 , con la dictación de la Ley $\mathrm{N}^{\circ} 12.435$ (publicada en Diario Oficial el 12 de febrero de 1957). El artículo 8 de dicha ley concede una asignación familiar para los hijos pensionados por muerte en accidente del trabajo del progenitor. En el artículo 9, se establece el goce en la preferencia para optar a becas que otorga el Estado en todas las ramas de la educación pública. Para los hijos de los accidentados fallecidos en accidentes de trabajo; y por último, en el artículo 11 se establece una norma marcada por el contexto de la Segunda Guerra Mundial: las viudas e hijos de tripulantes chilenos fallecidos en naufragios de barcos que navegaban en aguas extranjeras con bandera chilena (durante la guerra mundial, o sea, desde 1939 a 1945$)^{3738}$, tenían derecho a una pensión de accidente del trabajo, con cargo al Fondo de Garantía de la Ley 8918 (Díaz Salas, 1958: 238-239).

Ese mismo año se dicta la Ley 12.462 (6 de julio 1957, publicada en Diario Oficial) estableciendo en su artículo 9 dos pequeñas modificaciones al Decreto con Fuerza de Ley 245 sobre asignación familiar obrera: “b) Los hijos legítimos y naturales de cualesquiera de los cónyuges y los adoptados legalmente. Menores de 18 años o inválidos. c) Los hijos mayores de 18 años y menores de 23, que sigan cursos técnicos o universitarios de forma regular”. El artículo 10 limitó la extensión de este beneficio a solo dos hijos adoptados (Díaz Salas, 1958: 278-280).

Desde 1958 hasta 1970 se observa un alza de nuevas regulaciones y otras modificaciones legales que abarcan al menor de edad, variando desde beneficios previsionales hasta incluso derechos para celebrar ciertos contratos.

\footnotetext{
${ }^{37}$ Solo se registra un caso de naufragio de nave con bandera chilena: el hundimiento del vapor chileno Toltén (1858 TRG) del 13 de marzo de 1942, nave originalmente de origen danés bajo el nombre de "Lotta". Fue requisada por el Estado de Chile y entregada su operación a la Compañía Sudamericana de Vapores a través de la Armada, al no cumplir con las normas de disminución de tonelaje de carga exigidos. El siniestro tuvo lugar durante su navegación entre los puertos estadounidenses de Filadelfia y Nueva York. Aunque nunca se supo de qué nacionalidad fue el submarino que lo torpedeó a las 0230 horas de ese día, las sospechas recayeron contra las potencias del Eje, dadas las circunstancias bélicas que atravesaba el mundo y a las respuestas poco convincentes de las embajadas de las potencias del Eje. La investigación arrojó que la causa del hundimiento fue facilitada por haber sido obligada la nave a apagar sus luces en cumplimiento de una orden ineludible de un barco patrullero de guardacostas estadounidenses un par de horas antes (entre las 2100 y 2200 horas). Al no poder divisarse bien, con las luces apagadas, las banderas chilenas pintadas en el casco del barco. Debido a las dudas sobre el caso, nunca se indemnizó el daño de ninguna parte (Vargas Sáez, Juan Francisco. Algunos siniestros marítimos acaecidos en el siglo XX. Valparaíso, Chile. 2000. Páginas 269-271). La nómina de la tripulación arrojó 29 nombres, solo hubo un sobreviviente (el señor Julio Fausst Rivera) y un tripulante que quedó en tierra antes (señor Guillermo Ortega Flores). En: Pugh Gillmore, Kenneth. El vapor “Toltén”, torpedeado en 1942 en su recalada a Nueva York. Boletín de la Academia de Historia Naval y Marítima de Chile. Año XII, número 12. Valparaíso, Chile. 2009. Páginas 21 a 33.

${ }^{38}$ No se registran siniestros de este tipo en aguas nacionales. Bascuñán, Carlos; Eichholz, Magdalena y Harwig Fernando. Naufragios en el Océano Pacífico Sur. Aguilar Chilena de Ediciones. Santiago de Chile. 2003.
} 
La Ley $\mathrm{N}^{\circ} 13.305$ (publicada el 6 de abril de 1959) extiende el beneficio de asignación familiar a nietos huérfanos menores de 20 años (Díaz Salas, 1960: 251). En la misma Ley $\mathrm{N}^{\circ} 13.305$, en su artículo 60, se establece el derecho a percibir asignación familiar para los empleados y obreros, públicos o particulares, a cuyas expensas se encuentran sus nietos o bisnietos huérfanos, menores de 20 años y que no disfruten de renta (Díaz Salas, 1960: 251). En el artículo 43 se concedía un anticipo de pensión de orfandad mientras durara la tramitación de la misma.

La Ley 12,897 del 28 de junio de 1958, artículo 29, estableció que los hijos de un imponente de la Caja de Empleados Particulares, fallecido con anterioridad a la vigencia de la ley 19,977 del 14 de noviembre de 1955, tendrían el mismo derecho para la adquisición de una casa habitación u obtener préstamos hipotecarios, siempre que habitasen la casa que deseen adquirir (Díaz Salas, 1960: 251).

Posteriormente se establecerían, por ley, reajustes sobre las pensiones otorgadas. Dado que se extendían en precios nominales (no existían medidas reajustables como la Unidad de Fomento), en 1961 (15 mayo) se reajustaron las pensiones de orfandad de 4,2 escudos, equivalente al $20 \%$ del salario medio de pensiones $\left(\mathrm{E}^{\mathbf{o}} 21,11\right)$ vigente en el año 1961, según estableció la Ley 10383 en su artículo 44 (Díaz Salas, 1962: 378).

Ese mismo año, se modifica la Ley $\mathrm{N}^{\circ} 7295$ extendiendo la asignación familiar a favor de los empleados particulares, que justifiquen tener a su favor hijos legítimos o adoptivos, menores de 18 años y mayores de esta edad, pero menores de 23 años, que acrediten con certificados competentes, que siguen cursos regulares universitarios o de especialidad técnica (Díaz Salas, 1962: 378).

Más adelante, se dicta el Decreto Ley 1757 que "Otorga beneficios por accidentes y enfermedades a los miembros de los Cuerpos de Bomberos” (publicado el 7 abril de 1977), que estableció lo siguiente (Díaz Salas, 1977: 61-63):

- Su artículo 1, en la letra d), determina que en caso de muerte, la viuda y los hijos menores de 18 años, si los hubiere, legítimos o naturales, tendrían derecho a una renta vitalicia conjunta, equivalente a ocho sueldos vitales, con derecho a acrecer.

- Los hijos que hubieren cumplido 18 años, pero que tuvieren menos de $23 \mathrm{y}$ acrediten estar efectuando estudios secundarios, universitarios o técnicos, podrán seguir gozando de esta renta hasta cumplir esta última edad.

- Si hubiere hijos menores y la viuda falleciere, la pensión establecida corresponderá íntegramente a dichos hijos, por partes iguales y con derecho a acrecer, cancelándose al tutor o curador cuya representación se acredite satisfactoriamente ante la Superintendencia de Compañías de Seguros, Sociedades Anónimas y Bolsas de Comercio.

- Si hubiere hijos menores y la viuda contrajere nuevas nupcias, ésta tendrá derecho durante un año, a contar desde la fecha del matrimonio, al 40\% de la renta que le hubiere correspondido de haber continuado en su estado de viudez, correspondiendo el resto a los hijos menores durante ese periodo y acreciendo dicho $40 \%$ a los mismos menores una vez transcurrido el plazo indicado.

- A falta de viuda e hijos, la pensión corresponderá íntegramente a los ascendientes y descendientes que hubieran vivido a expensas del fallecido. 
Desde luego que el alcance de la norma anterior estaba restringido a familiares del bombero causante. Cabe también destacar que la labor del bombero en Chile es voluntaria hasta el día de hoy, por lo que no recibe ninguna remuneración por sus servicios, siendo llamativo que se establezcan las pensiones en base a criterios legales y no respecto de la remuneración correspondiente, que obviamente no procede en este caso por no existir.

\subsubsection{REGULACIÓN RELATIV A A BENEFICIOS HABITACIONALES.}

La Ley 14118 (11 octubre 1960) dispuso que el cónyuge sobreviviente e hijos de un imponente de la Caja de Previsión de Empleados Particulares tendría derecho a continuar la operación hipotecaria para materializar la adquisición de la casa habitación que le hubiera sido asignada siempre que la habiten ellos mismos. La Caja les concederá un préstamo hipotecario al mismo interés y amortización que pagan los imponentes activos (Díaz Salas, 1977: 390-391).

Quizás la norma más destacable sea la Ley $\mathrm{N}^{\circ} 14.171$ sobre reconstrucción nacional (venta de inmuebles del Servicio de Seguridad Social) del 26 octubre de 1960, surgida como consecuencia del Terremoto del mismo año. En su artículo 7 transitorio, se facultaba al Consejo del Servicio de Seguridad Social para vender casas o departamentos en las poblaciones obreras a las viudas o hijos herederos de imponentes que, a la fecha del fallecimiento, ocupaban la propiedad pero no habían suscrito la escritura de compraventa (Díaz Salas, 1977: 361-362).

\subsubsection{REGULACIÓN RELATIVA AL CUIDADO DEL MENOR DE EDAD DE PARTE DEL ESTADO}

Llegado el año 1962, se dicta el Decreto 2787 (5 octubre 1962) que modifica la Ley 4447 de menores, estableciendo que la función de cuidar de forma personal a los menores, cuando corresponda al Estado, se ejercerá a través del Servicio Nacional de Salud (artículo 1 de la Ley 4447). Además de fijar las penas de prisión en cualquiera de sus grados o prisión menor en su grado mínimo, o con multa de diez a cien escudos a quien (Díaz Salas, 1965: 506).

Ocupe a menores de 21 años en trabajos u oficios que los obliguen a permanecer en cantinas o casas de prostitución o juego.

1. El empresario, propietario o agente de espectáculos públicos en que menores de 16 años hagan exhibiciones de agilidad, fuerza u otros semejantes con propósitos de lucro.

2. El que ocupe menores de 16 años en trabajos nocturnos entre las 10 de la noche y las 5 de la mañana.

3. El padre o madre o persona a cuyo cuidado esté el menor:

a. Que lo maltraten de forma habitual o inmotivadamente.

b. Que lo abandonen sin velar por su crianza o educación.

c. Que lo corrompan.

Sigue en curso 1962 y aparece el Decreto 2788 (5 octubre) que modifica la Ley $\mathrm{N}^{\circ}$ 5.750. En el artículo 3 de dicha ley se establece que será competente para conocer de las demandas de alimentos deducidas por el cónyuge o los hijos menores el de la residencia del 
alimentario; pero si éste se cambiare de domicilio por abandono de hogar o rapto, será competente el del alimentante. Los juicios de alimentos que se deban a menores serán de conocimiento del Juez de Letras de Menores y se tramitarán con arreglo a la ley sobre protección de menores (Díaz Salas, 1965: 506).

\subsubsection{MODIFICACIONES A LAS PROHIBICIONES LEGALES.}

Llegado 1965, aparece la primera modificación directa al texto del Código del Trabajo por la Ley $\mathrm{N}^{\circ} 16.311$ (del 29 de septiembre de dicho año), agregándose un nuevo inciso al artículo 136 (que prohíbe el trabajo fuera de las horas establecidas por la empresa, sea para el trabajo general o el de equipos): se extiende la prohibición del mismo a los menores de 18 años que tengan la calidad de empleados particulares (inciso $3^{\circ}$ ) (Díaz Salas, 1966).

\subsubsection{MODIFICACIONES TRAS LA IMPLEMENTACIÓN DEL "PLAN LABORAL".}

Durante el gobierno de Augusto Pinochet se da un nuevo énfasis al Derecho del Trabajo. La nueva doctrina económica traída por los economistas formados en Estados Unidos, de talante más liberal, requiere una nueva legislación laboral que respalde su desarrollo, lo que culminaría con el llamado "Plan Laboral" en nuestra materia.

El llamado "Plan Laboral" se materializó mediante el Decreto Ley $\mathrm{N}^{\circ} 2.200$, publicado el 15 de junio de 1978, proponiéndose reformar la legislación laboral vigente, orientándose a una mayor flexibilidad en el mercado laboral, acorde a las reformas económicas estructurales que fueron tomadas en aquellos años.

\subsubsection{MODIFICACIONES EN MATERLA DE CAPACIDAD DE CONTRATAR DEL MENOR DE EDAD Y DE PROHIBICIONES LEGALES.}

El artículo 23 del DL 2200 indica las capacidades de contratación de los menores de $\operatorname{edad}^{39}$. No hay variaciones respecto del texto original del Código de 1931, salvo la

\footnotetext{
${ }^{39}$ El artículo 23 del DL 2200 dice: "Para los efectos de las leyes laborales, se considerarán mayores de edad y pueden contratar libremente la prestación de sus servicios los mayores de 18 años.

Los menores de 18 años y mayores de 15 pueden celebrar contratos de trabajo si cuentan con autorización expresa del padre o madre; a falta de ellos, del abuelo paterno o materno; o a falta de éstos, de los guardadores, personas o instituciones que hayan tomado a su cargo al menor, o a falta de todos los anteriores, del inspector del trabajo respectivo.

Los menores de 15 años y mayores de 14 pueden contratar la prestación de sus servicios, siempre que cuenten con la autorización indicada en el inciso anterior, hayan cumplido con la obligación escolar, y sólo realicen trabajos ligeros que no perjudiquen su salud y desarrollo, que no impidan su asistencia a la escuela y su participación en programas educativos o de formación.

El inspector del trabajo que hubiere autorizado al menor en los casos de los incisos anteriores, pondrá los antecedentes en conocimiento del juez de menores que corresponda, el que podrá dejar sin efecto la autorización si la estimara inconveniente para el trabajador.

Otorgada la autorización, se aplicarán al menor las normas del artículo 246 del Código Civil y será considerado plenamente capaz para ejercitar las acciones correspondientes.

Lo dispuesto en el inciso segundo no se aplicará a la mujer casada, quien se regirá al respecto por lo previsto en el artículo 150 del Código Civil.

En ningún caso, los menores de 18 años podrán trabajar más de 8 horas diarias”.
} 
agregación de la autorización supletoria del Inspector del Trabajo correspondiente, cuando falten todos las personas cuyo consentimiento la ley exige.

Respecto de las prohibiciones ${ }^{40}$ tampoco hay novedades en nuestra materia.

El artículo 28 de dicha norma ${ }^{41}$ establece una sanción por contratar a un menor no habilitado para el trabajo por su padre o madre o quien lo tuviese a su cuidado. El artículo $29^{42}$ tampoco incluye novedades respecto de la legislación anterior.

Más adelante, en el artículo 151 regulando sobre el contrato de aprendiz ${ }^{43}$, se establecen ciertas condiciones para proceder en la contratación de un menor de 21 años y mayor de 14, básicamente condiciones de escolaridad previas.

Finalmente indica que la Ley $\mathrm{N}^{\circ} 18.018$ derogó el artículo 151 del D.L. 2.200 (Código del Trabajo), en 1978 (Plan Laboral), que limitaba el contrato de aprendiz (sobre menores de 21 años).

Llegado 1982, nos encontramos con la Crisis Económica del mismo año. Solo hay en dicha edición del Código de Juan Díaz Salas unas pocas alusiones sobre disposiciones de contratación (del Decreto Ley 2200 de 1978) en artículos 23, 24 y 52.

Se modifica el artículo 23 del D.L. 2.200 estableciendo que:

- Los mayores de edad (de 18 años en adelante) pueden contratar libremente.

- De 15 a 18 años solo si cuentan con autorización expresa del padre o madre, y a falta de ellos el abuelo paterno o materno, o a falta de éstos, de los guardadores, personas o instituciones que hayan tomado a su cargo al menor, o a falta de todos los anteriores, del inspector del trabajo respectivo.

- De 14 a 15 años, pueden contratar siempre que cuenten con autorización del inciso anterior, y hayan cumplido con la obligación escolar, y sólo realicen trabajos ligeros que no perjudiquen su salud y desarrollo, que no impidan su

${ }^{40}$ El artículo 24 del DL 2200 dice: "Los menores de 18 años de edad no serán admitidos en trabajos subterráneos, ni en faenas que requieran fuerzas excesivas, ni en actividades que puedan resultar peligrosas para su salud, seguridad o moralidad.

Los menores de 21 años no podrán ser contratados para trabajos subterráneos sin someterse previamente a un examen de aptitud.

El empleador que contratare a un menor de 21 años sin haber cumplido el requisito establecido en el inciso precedente incurrirá en una multa de dos a cinco ingresos mínimos mensuales, la que se duplicará en caso de reincidencia”.

${ }^{41}$ El artículo 28 del DL 2200 dice: "Si se contratare a un menor sin sujeción a lo dispuesto en los artículos precedentes, el empleador estará sujeto a todas las obligaciones inherentes al contrato mientras se aplicare; pero el inspector del trabajo, de oficio o a petición de parte, deberá ordenar la cesación de la relación y aplicar al empleador las sanciones que correspondan”.

${ }^{42}$ El artículo 29 del DL 2200 dice: "Queda prohibido a los menores de 18 años todo trabajo nocturno en establecimientos industriales, que se ejecuten entre las 22 y las 7 horas, con excepción de aquellos en que únicamente trabajen miembros de la familia, bajo la autoridad de uno de ellos.

Exceptúase de esta prohibición a los varones mayores de dieciséis años en las industrias que determine el reglamento tratándose de trabajos que, en razón de su naturaleza, deban necesariamente continuarse de día y de noche".

${ }^{43}$ El artículo 151 dice: "Podrán celebrar el contrato de aprendizaje los trabajadores menores de 21 años y mayores de 14 que hayan egresado de la enseñanza básica. Sin embargo, en casos calificados, el Servicio Nacional de Capacitación y Empleo podrá autorizar la celebración de contratos de aprendizaje para aquellos que no hayan egresado de esa enseñanza”. 
asistencia a la escuela y su participación en programas educativos o de formación.

El artículo 24 establece que los menores de 18 años no serán admitidos en trabajos subterráneos, ni en faenas que requieran fuerzas excesivas ni en actividades que puedan resultar peligrosas para su salud, seguridad o moralidad.

Los menores de 21 años no podrán ser contratados para trabajos subterráneos sin someterse a un examen de aptitud previamente.

La sanción por contratar a un menor de 21 años sin cumplir lo anterior, será una multa de 2 a 5 ingresos mínimos mensuales, la que se duplicará en caso de reincidencia.

El artículo 52 inciso $4^{\circ}$ indica que la remuneración mínima establecida en el inciso tercero del mismo artículo no será aplicable a los trabajadores menores de 21 años, hasta que cumplan dicha edad, ni a los mayores de 65 años, casos en que se estará a la remuneración que libremente convengan las partes.

Llegamos hasta el último tomo de la gran recopilación de Juan Díaz Salas. En él figura el Decreto con Fuerza de Ley $\mathrm{N}^{\circ} 150$ (25 de marzo 1982), artículo 3, que concede asignación familiar por los hijos, los adoptados, nietos y bisnietos menores de 18 años. Concede también una asignación por los hijos mayores de 18 años hasta los 24 años, solteros estudiantes.

Por último, se dicta la Ley $\mathrm{N}^{\circ} 18.020$ de subsidio familiar para personas de escasos recursos. En su artículo 2, establece que serán causantes del subsidio familiar los menores hasta 8 años de edad, que vivan a expensas del beneficiario, que participen de programas de salud del Ministerio de Salud para la atención infantil, y que no disfruten de una renta igual o superior al monto del subsidio cualquiera sea su procedencia. Sobre los niños de más de 6 años, para tener derecho al subsidio, deberá acreditarse que es alumno regular de educación básica, a menos que se acredite que se encuentra en alguna situación de excepción de la Ley de Instrucción Primaria.

\subsubsection{MODIFICACIONES RELATIVAS A BENEFICIOS PREVISIONALES.}

No vuelve a haber nuevas menciones del menor hasta 1981, con el Plan Laboral ya en consolidación. El Decreto Ley $\mathrm{N}^{\circ} 3626$ que "Introduce modificaciones a los decretos leyes $n^{\circ} 3500$ de 1980 y 824 de 1974" (publicado el 21 de febrero de 1981), realiza un par de modificaciones menores. La única referente al menor de edad es la de su artículo 1 número 2 modificando al Decreto N³.500 de 1980 (Díaz Salas, 1977: 528): "Sustitúyese el inciso segundo del artículo 6 por Estas limitaciones no se aplicarán si a la época del fallecimiento la cónyuge se encontrare embarazada o si quedaren hijos comunes".

La otra modificación es la que figura en número 3, que remplaza el artículo 7 del Decreto 3500 por lo siguiente: "El cónyuge sobreviviente para ser beneficiario de pensión de sobrevivencia, debe ser inválido en los términos establecidos en el artículo 4, y concurrir las exigencias establecidas en el inciso primero de artículo anterior a menos que quedaren hijos comunes".

Siguiendo con el desarrollo de la legislación, en 1981 se dicta la Ley 18.020 que "Establece subsidio familiar para personas de escasos recursos y modifica normas que indica" (publicado el 17 de agosto de 1981). En su artículo 2 establece que serán causantes 
del subsidio familiar los menores hasta los ocho años de edad, que vivan a expensas del beneficiario, que participen en programas de salud establecidos por el Ministerio de Salud para la atención infantil y que no disfruten de una renta igual o superior al monto del subsidio cualquiera sea su origen o procedencia. No considera renta la pensión de orfandad (Díaz Salas, 1982: 251).

Respecto de los niños de más de 6 años de edad, para tener derecho al subsidio deberá acreditarse, además que es alumno regular de instrucción básica, a menos que se acredite que el niño se encuentra en alguna de las situaciones de excepción que contempla la Ley de Instrucción Primaria, contenida en el Decreto con Fuerza de Ley $\mathrm{N}^{\circ}$ 5291, de $1930^{44}$.

En el artículo 3 establecen como beneficiarios del subsidio familiar a la madre, y en su defecto, al padre del causante, cumpliendo los requisitos del artículo de:

a. Haber solicitado por escrito el beneficio, en la municipalidad de su domicilio.

b. No haber percibido un ingreso superior a cuarenta y ocho unidades tributarias mensuales $^{45}$ durante el año calendario anterior a aquél en que se perciba efectivamente el beneficio.

c. No estar en situación de proveer por sí solo o en unión del grupo familiar señalado en la letra anterior, a la mantención y crianza del causante, atendidas las condiciones sociales y económicas del beneficiario.

Y así culminamos la revisión de la obra recopiladora de Juan Díaz Salas, quien nos dejó una serie de 24 tomos donde recopiló los textos refundidos del Código del Trabajo y las leyes complementarias que surgieron a lo largo de su vigencia.

\footnotetext{
${ }^{44}$ El artículo 2 del Decreto con Fuerza de Ley n ${ }^{\circ} 5291$ de 1930 indica dicha obligación de escolaridad: "Todo niño, de uno u otro sexo y de siete a quince años cumplidos, está obligado a asistir a la escuela con el fin de recibir la educación primaria correspondiente y el grado de especialización vocacional, siempre que no continúe el cumplimiento de la obligación en el primer ciclo de educación secundaria.

Si obtiene alguna ocupación de carácter permanente, continuará sometido a esta obligación hasta los dieciséis años de edad, debiendo satisfacerla en alguna escuela suplementaria o complementaria”.

${ }^{45}$ La Unidad Tributaria Mensual (UTM) fue creada por el Código Tributario (Decreto Ley 830 de 1974, publicado el 31 de diciembre del mismo año). Aquella norma lo consagra en su artículo 8 número 10: "Por "unidad tributaria", la cantidad de dinero cuyo monto, determinado por ley y permanentemente actualizado, sirve como medida o como punto de referencia tributario; y por "unidad tributaria anual", aquella vigente en el último mes del año comercial respectivo, multiplicada por doce o por el número de meses que comprenda el citado año comercial. Para los efectos de la aplicación de las sanciones expresadas en unidades tributarias, se entenderá por "unidad tributaria anual" aquella que resulte de multiplicar por doce la unidad tributaria mensual vigente al momento de aplicarse la sanción.

La unidad tributaria mensual o anual se expresará siempre en miles de pesos, despreciándose las cifras inferiores a cincuenta centavos y elevándose las iguales o mayores a esta suma al entero superior".

Si bien la norma fue rectificada por el Decreto Ley 1244 del 8 de noviembre de 1975, no se modificó nada sustancial respecto de la Unidad Tributaria Mensual, sino respecto de las sanciones por el no cumplimiento de los deberes tributarios o por infracciones al Código Tributario: "Para los efectos de la aplicación de las sanciones expresadas en unidades tributarias, se entenderá por "unidad tributaria anual" aquella que resulte de multiplicar por doce la unidad tributaria mensual vigente al momento de cometerse la Infracción" (artículo 8, letra a. del Decreto Ley 1244).

La última modificación a ese apartado es aún más pequeña, de parte de la Ley 19506 del 30 de julio de 1997 , que en su artículo 3 número 1 establece: "En el inciso primero del $N^{o} 10$ del artículo 8", sustitúyese la expresión "al momento de cometerse la infracción." por "al momento de aplicarse la sanción."”.
} 


\section{CONSIDERACIONES FINALES}

Desde el punto de vista exegético, se podría decir que se protegió al menor de edad. Sin embargo, como dice el dicho "el papel todo lo aguanta", otra cosa es cómo se aplicó la ley por parte de los tribunales y los organismos administrativos encargados de velar por la protección de la parte más débil en la relación laboral.

La tentativa de entender cómo se aplicaron estas normas pasa necesariamente por el tratamiento jurisprudencial durante la época de vigencia del Código del Trabajo de 1931. Asimismo, vale destacar la jurisprudencia administrativa sobre el mismo tema, pues el primer contacto entre el menor afectado por una vulneración de sus derechos y el Estado se da por medio de la fiscalización que hacían los organismos encargados en aquella época, a saber, la Dirección del Trabajo.

Por último, cabe destacar cuáles fueron los contenidos de los proyectos de ley que sirvieron de base al Código. Para estos efectos, se puede consultar el trabajo matriz que orienta este artículo (Candiani, 2015), donde se realiza un análisis más detallado de los dictámenes, sentencias judiciales y opiniones doctrinarias surgidas en esta materia por aquellos años.

\section{BIBLIOGRAFIA}

BASCUÑÁN, Carlos, et al, (2003), Naufragios en el Océano Pacífico Sur, (Aguilar Chilena de Ediciones. Santiago de Chile).

CANDIANI, Andrei, (2015), Estatuto jurídico del menor de edad en el Código del Trabajo de 1931, (Memoria para optar al grado de Licenciado en Ciencias Jurídicas y Sociales. Universidad de Chile. Santiago).

DÍAZ SALAS, Juan, (1962), Código del Trabajo, Tomo X, (Santiago de Chile. Editorial Nascimento).

DÍAZ SALAS, Juan, (1970), Código del Trabajo, Tomo XIV, (Santiago de Chile. Editorial Nascimento).

DÍAZ SALAS, Juan, (1958), Código del Trabajo, Tomo VIII, Santiago de Chile. Editorial Nascimento.

DÍAZ SALAS, Juan, (1960), Código del Trabajo, Tomo IX, (Santiago de Chile. Editorial Nascimento).

DÍAZ SALAS, Juan, (1977), Código del Trabajo. Tomo XVII, (Santiago de Chile, Editorial EDIMPRES).

DÍAZ SALAS, Juan, (1965), Código del Trabajo, Tomo XI, (Santiago de Chile, Editorial Nascimento).

DÍAZ SALAS, Juan, (1977), Código del Trabajo, Plan Laboral actualizado. Nuevo sistema de pensiones. (Santiago de Chile, Tomo XXI, Editorial Edimpres).

DÍAZ SALAS, Juan, (1982) Código del Trabajo, Tomo XXII, (Santiago de Chile. Editorial Cepet).

DÍAZ SALAS, Juan, (1966), Código del Trabajo, Tomo XII, (Santiago de Chile. Editorial Nascimento). 
DÍAZ SALAS, Juan, (1977), Código del Trabajo: Plan Laboral actualizado. Nuevo sistema de pensiones. Tomo XXI. Santiago de Chile. Editorial Edimpres.

GUZMÁN BRITO, Alejandro, (1993), Codificación, descodificación y recodificación del Derecho Civil Chileno. (Revista de Derecho y Jurisprudencia y Gaceta de los Tribunales. Tomo CX, $\mathrm{N}^{\circ}$ 1. Enero-Abril)

IRTI, Natalino, (1992), La Edad de la Descodificación, (Barcelona, España, José María Bosch Editor).

MARX Y ENGELS, (2008), El Manifiesto Comunista, (Santiago de Chile, Editorial La Copa Rota, Serie The Clinick Pocket).

MONTT BALMACEDA, Manuel, (1998), Principios de Derecho Internacional del Trabajo: la O.I.T. (Santiago de Chile. Editorial Jurídica de Chile, Segunda Edición).

LEÓN XIII. Carta Encíclica Rerum Novarum del Sumo Pontífice León XIII sobre la situación de los obreros. [en $<$ http://www.vatican.va/holy_father/leo_xiii/encyclicals/documents/hf_lxiii_enc_15051891_rerum-novarum_sp.html> [consulta: 05 octubre 2011].

PUGH GILLMORE, Kenneth, (2009), El vapor “Toltén”, torpedeado en 1942 en su recalada a Nueva York. (Valparaíso, Chile, Boletín de la Academia de Historia Naval y Marítima de Chile. Año XII, número 12)

ROJAS FLORES, Jorge, (2010), (Historia de la Infancia en el Chile Republicano), Ocho Libros Editores. 2010.

RUIZ DE GAMBOA, Alberto y Díaz Salas, Juan, (1942), Código del Trabajo, Tomo I, (Santiago de Chile, Editorial Nascimento).

RUIZ DE GAMBOA, Alberto y Díaz Salas, Juan, (1942), Código del Trabajo, Tomo II, (Santiago de Chile. Editorial Nascimento).

SALAS, Darío, (2011), El Problema Nacional, [Santiago de Chile. Biblioteca Fundamentos de la Construcción de Chile (Cámara Chilena de la Construcción, Pontificia Universidad Católica de Chile y Biblioteca Nacional)].

SALAZAR, Gabriel, (2007), Ser niño “huacho" en la historia de Chile, (Santiago de Chile. Editorial LOM.).

THAYER ARTEAGA, Willliam, (2008), Dimensión Histórica del Código del Trabajo, (Santiago de Chile, Ediciones Universidad del Desarrollo).

WALKER LINARES, Francisco, (1957), Nociones elementales de Derecho del Trabajo, (Santiago de Chile, Editorial Nascimento, Quinta edición refundida). 